\title{
Tree biomass and carbon density estimation in the tropical dry forest of Southern Western Ghats, India
}

\author{
Babu Padmakumar ${ }^{(1)}$, \\ Naduparambu P Sreekanth ${ }^{(2)}$, \\ Viswanathan Shanthiprabha ${ }^{(2)}$, \\ Joby Paul ${ }^{(1)}$, \\ Kasau Sreedharan ${ }^{(1)}$, \\ Toms Augustine ${ }^{(1)}$, \\ Kazhuthuttil K Jayasooryan (1), \\ Mutharimettak Rameshan ${ }^{(1)}$, \\ Mahesh Mohan ${ }^{(1)}$, \\ Eswara V Ramasamy ${ }^{(1)}$, \\ Ambattu P Thomas ${ }^{(2)}$
}

\begin{abstract}
United Nations Framework Convention on Climate Change highlights the significance of carbon storage and emission in forests towards climate change mitigation. The aim of this study was to quantify the tree biomass and carbon density (carbon storage) in the tropical dry forest of the Chinnar Wildlife Sanctuary of Kerala located in the Southern Western Ghats, India. We investigated the species-wise contribution of carbon (C) storage, as well as the species-wise and plot-wise correlation between carbon and other dendrometric variables. We also analysed the girth (diameter) wise distribution of carbon and tree density in the study region. The study was conducted in eight selected sample plots of the region, each with an area of 0.1 hectare. Species-specific volume and specific gravity relationship coupled with suitable regression equation were used to estimate biomass. Tree carbon was assumed to be $47 \%$ of the biomass. The results showed that the average biomass and carbon density of the vegetation were $64.13 \mathrm{t} \mathrm{ha}^{-1}$ and $30.46 \mathrm{t}-\mathrm{C} \mathrm{ha}{ }^{-1}$, respectively. Among the 32 species identified, Tamarindus indica L. (17\%), Hardwickia binata Roxb. (14\%), Terminalia arjuna (Roxb. ex DC.) Wight \& Arn (10\%) and Pleiospermium alatum (Wight \& Arn.) Swingle (10\%) were dominant as for carbon storage. The correlation analysis showed that basal area is a good predictor of tree biomass and carbon, while the role of tree density and tree diversity remain uncertain in determining carbon storage. With respect to diametric class distribution, tree density showed a reverse $\mathrm{J}$-shaped pattern indicating the sustainable regeneration of the analysed forest, where the small- (diameter at breast height $3-9 \mathrm{~cm}$ ) to medium-sized trees (diameter at breast height 10-69 cm) were found to contribute to more than $50 \%$ of biomass and carbon in the forest. The study provides useful information for carbon mitigation strategies in a tropical dry forest in the Southern Western Ghats.
\end{abstract}

Keywords: Above Ground Tree Biomass, Carbon, Tropical Dry Forest, Kerala, Southern Western Ghats

change scenario, the international community is increasingly made aware of the fact that the alleviation of global warming cannot be achieved without the inclusion of forests in the mitigation plan. Reducing Emissions from Deforestation and Forest Degradation and enhancing forest carbon (REDD+) is a new initiative of the United Nations Framework Convention on Climate Change (UNFCCC). It is led by developing countries with rich forest cover and calls
(1) School of Environmental Sciences, Mahatma Gandhi University, Kottayam 686560 (India); (2) Advanced Centre of Environmental Studies and Sustainable Development (ACESSD), Mahatma Gandhi University, Kottayam 686560 (India)

@ Babu Padmakumar (babupk.ktm@gmail.com)

Received: Aug 04, 2016 - Accepted: Jun 05, 2018

Citation: Padmakumar B, Sreekanth NP, Shanthiprabha V, Paul J, Sreedharan K, Augustine T, Jayasooryan KK, Rameshan M, Mohan M, Ramasamy EV, Thomas AP (2018). Tree biomass and carbon density estimation in the tropical dry forest of Southern Western Ghats, India. iForest 11: 534-541. - doi: 10.3832/ifor2190-011 [online 2018-08-01]

Communicated by: Tamir Klein for economic incentives to reduce the emissions of greenhouse gases from deforestation and forest degradation in developing countries (Gibbs et al. 2007). Beyond carbon sequestration, REDD+ is also expected to play a major role in other ecosystem services and has the potential to generate benefits for indigenous and local communities. To achieve and optimize these "co-benefits", the developing countries need to have well-established estimates of forest carbon densities or stocks for a successful implementation of mitigating policies and to take advantage of the REDD+ programme (Saatchi et al. 2011). According to Canadell \& Raupach (2008), increasing the carbon density or stock of existing forests is also an important option in this regard. It is therefore vital to understand the potential role of forests, especially tropical forest, in curtailing the impact of global warming. As the climate change debate progresses, policy makers also require more scientific and reliable information on the current status of carbon storage that would benefit in effective resource management, in developing policies and setting priorities for the forest in 
Southern Western Ghats, India.

Tropical dry forests represent $42 \%$ of the landmass in the tropics (Miles et al. 2006) and are estimated to detain $110 \mathrm{Gt}$ (giga tonne) vegetation carbon compared to 134 $G$ t vegetation carbon in tropical rainforests (Foley 1995). Among the major tropical forest types, tropical dry forests are the most threatened, as about $90 \%$ of these forests are exposed to a variety of threats largely resulting from human activity (Miles et al. 2006). Further, while tropical rainforests are the most studied among the tropical forest types, the seasonally dry tropical forests have been seriously neglected (Dirzo et al. 2011). These forests are characterized by seasonal rainfall, with several months of severe drought in the annual cycle (Mooney et al. 1995). Regarding the total forest cover in India, tropical dry deciduous forests cover an area of $34.80 \%$ followed by tropical moist deciduous forests (33.19\%), tropical semi evergreen forests $(7.72 \%)$ and tropical wet evergreen forests $(7.54 \%$ Reddy et al. 2015). Various attempts were made in the recent past to evaluate biomass and carbon density/stock in different forest types in India and these estimates exhibit large temporal and spatial variation. Hence, it is important to develop suitable biomass estimation methods which minimize errors for accurate and consistent reporting of forest carbon inventories.

The Western Ghats (south-western India) is known for its rich biodiversity and endemism, and is prone to high risk of anthropogenic impacts in the form of deforestation, developmental activities, expansion of plantations and habitat fragmentation (Molur et al. 2011). Any alterations in this ecosystem can directly contribute to carbon emission, thus turning it in a potential carbon source. Therefore, it is inevitable to appraise the status of forests in terms of regional terrestrial carbon storage and their role in global warming abatement. Although there is a growing interest in estimating the biomass of forests and their role in carbon cycling, a baseline database involving tree biomass and carbon are lacking from the tropical dry forests of Chinnar in Southern Western Ghats.

In the present study, we included smalldiameter trees $(\mathrm{DBH}<10 \mathrm{~cm})$, which are generally ignored in carbon sequestration studies due to the absence of suitable equations, thereby improving the precision and accuracy of biomass and carbon estimation. This will provide a strong basis for management programmes which prioritize carbon sequestration in the tropical dry forest of Chinnar in Southern Western Ghats. Our main objectives were: (i) to estimate tree biomass and carbon density of the forest ecosystem; (ii) to identify the major carbon storing tree species in the ecosystem; (iii) to examine the both species- and plot-wise relationship between carbon and other stand variables (dendrobiometric variables); (iv) to investigate the distribution of carbon among different diametric classes along with tree density in the area. The hypotheses tested in this study were: (i) dendrobiometric variables like basal area, tree density and tree diversity are good indicators and predictors of biomass and carbon of the system; (ii) smaller to medium trees have a greater role in carbon storage compared to the larger trees in the tropical dry forest.

\section{Materials and methods}

\section{Study area}

The study region is the lower area of southern tropical dry forest in the Chinnar Wildlife Sanctuary (400-500 $\mathrm{m}$ a.s.l.) in Idukki district of Kerala, India. It is situated

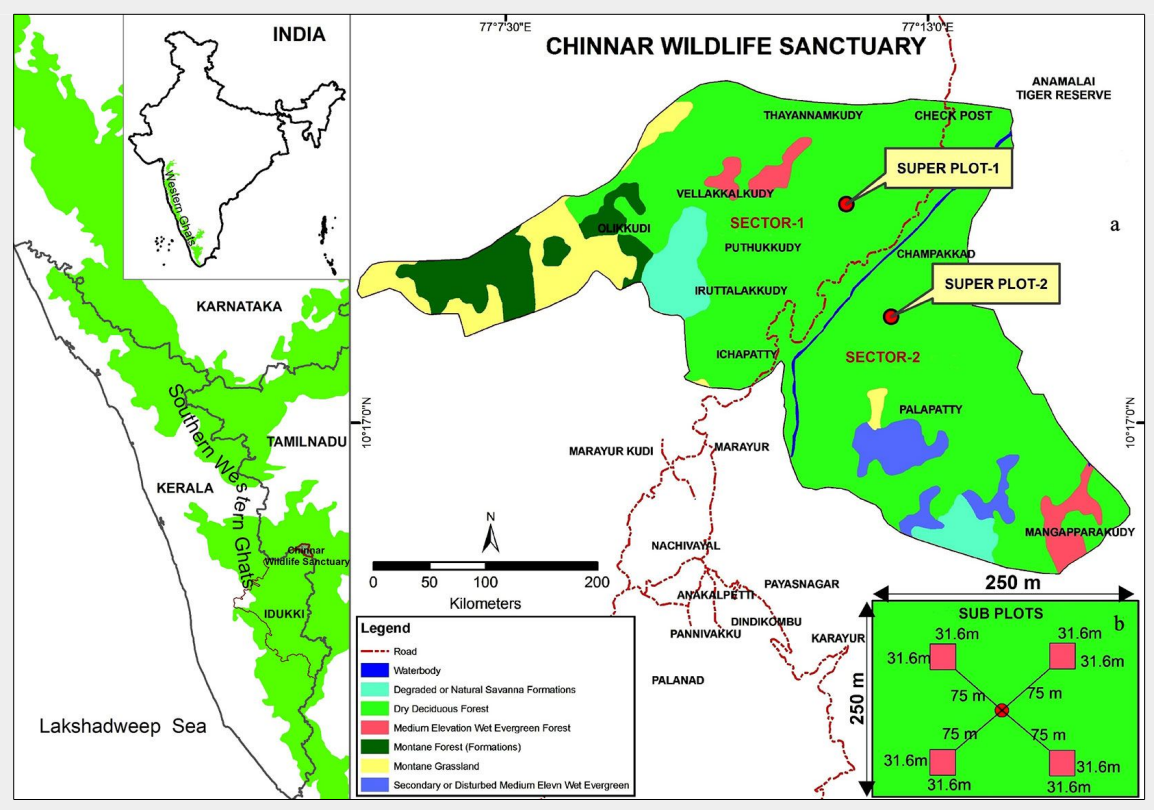

Fig. 1 - Location of the study area (a) and scheme of the sampling plots (b). in the Southern Western Ghats part of peninsular India (Fig. 1a). Chinnar Wildlife Sanctuary comprises an area of 9,044 ha located between $77.09568^{\circ} \mathrm{E}-77.20435^{\circ} \mathrm{E}$ longitude and $10.25063^{\circ} \mathrm{N}-10.35212^{\circ} \mathrm{N}$ latitude, along the rain shadow region of the Southern Western Ghats. The terrain is undulating and rocky and the annual rainfall ranges from 300 to $500 \mathrm{~mm}$ in Chinnar (Kallarackal \& Somen 1999). Since the area is located in the rain shadow region, unlike most forests of Kerala, only about 48 rainy days occur in a year during the northeast monsoon. The temperature ranges from a minimum of $13{ }^{\circ} \mathrm{C}$ during December to a maximum of $37.8^{\circ} \mathrm{C}$ during April and May. The dry period lasts for 6-7 months at the lower elevations, while it shorter at higher altitude. Relative humidity also varies from 19 to $100 \%$ during the rainy months of October and November (KFD 2012). The climate of Chinnar is generally dry and soil is sandy loam with weak fine granular structure (Chandrashekara et al. 1998). The dominant height of vegetation is up to $16 \mathrm{me}$ ters in the dry deciduous forest, which covers about $50 \%$ of the total forest area (KFD 2012). The main tree species are Pleiospermium alatum (Wight \& Arn.) Swingle, Canthium coromandelicum (Burm.f.) Alston, and Atalantia monophylla DC. Other major species include Chloroxylon swietenia DC. Cordia sinensis Lam., Acacia planifrons Wight \& Arn., Azadirachta indica A. Juss., Dichrostachys cinerea (L.) Wight \& Arn., Tamarindus indica L., Sapindus emarginatus Vahl , Cordia gharaf (Forssk.) Ehrenb. ex Asch, Lepisanthes tetraphylla (Vahl) Radlk., Vitex leucoxylon L.f., Sapindus emarginatus Vahl (see Tab. S1 in Supplementary material). Although the region falls within the protected area, anthropogenic interference such as tribal settlements and interstate highway (road) passing through the sanctuary poses quite a few threats to the biota in the ecosystem.

\section{Sampling and data collection}

The adopted methodology for data collection is mainly from the Intergovernmental Panel on Climate Change guidelines (IPCC 2006) for terrestrial carbon inventory specifically under land use, land use change and forestry (LULUCF) category, as well as from the field manual for vegetation carbon pool assessment of India (Singh \& Dadhwal 2009). For the purpose of sampling, species composition, topography, soil type and climatic conditions of the dry forest were taken into account. The whole area was subdiveded in two main sectors, which are split by a stream and a road (Fig. 1). A major plot (hereafter called "super plot") of $250 \times 250 \mathrm{~m}$ was randomly established in each sector. Four subplots of 31.6 $\times 31.6 \mathrm{~m}$ ( $0.1 \mathrm{ha})$ were then established in the four corners of each super plot, whose distance from the center of the major plot was $75 \mathrm{~m}$ (Fig. 1b). Such eight subplots from the two sectors were surveyed for the carbon inventory of the dry forest. Tree 
Tab. 1 - List of volume equations and specific gravity values used in the present study. (*): Average specific gravity; (GV): generalized volume equation; (V): species-specific volume equation; (D): diameter at breast height; (H): tree height.

\begin{tabular}{|c|c|c|c|}
\hline No. & Tree species & Volume equation & $\begin{array}{c}\text { Specific } \\
\text { gravity }\end{array}$ \\
\hline 1 & Albizia amara (Roxb.) B.Boivin & $V=-0.033-0.526 \cdot D+6.396 \cdot D^{2}$ & 0.950 \\
\hline 2 & Atalantia monophylla DC. & $G V=0.16948-1.85075 \cdot D+10.63682 \cdot D^{2}$ & * \\
\hline 3 & Azadirachta indica A.Juss. & $G V=0.16948-1.85075 \cdot D+10.63682 \cdot D^{2}$ & 0.680 \\
\hline 4 & Bauhinia racemosa Lam & $V=-0.04262+6.09491 \cdot D^{2}$ & * \\
\hline 5 & Canthium coromandelicum (Burm.f.) Alston & $G V=0.16948-1.85075 \cdot D+10.63682 \cdot D^{2}$ & 0.805 \\
\hline 6 & Canthium sp. & $G V=0.16948-1.85075 \cdot D+10.63682 \cdot D^{2}$ & 0.805 \\
\hline 7 & Chloroxylon swietenia DC. & $G V=0.16948-1.85075 \cdot D+10.63682 \cdot D^{2}$ & 0.980 \\
\hline 8 & Commiphora berri (Arn.) Engl. & $G V=0.16948-1.85075 \cdot D+10.63682 \cdot D^{2}$ & * \\
\hline 9 & Commiphora caudata (Wight \& Arn.) Engl. & $G V=0.16948-1.85075 \cdot D+10.63682 \cdot D^{2}$ & * \\
\hline 10 & Cordia gharaf (Forssk.) Ehrenb. ex Asch & $V=-0.49388+7.56417 \cdot D-31.45373 \cdot D^{2}+50.93877 \cdot D^{3}$ & 0.495 \\
\hline 11 & Dichrostachys cinerea (L.) Wight \& Arn. & $G V=0.16948-1.85075 \cdot D+10.63682 \cdot D^{2}$ & * \\
\hline 12 & Diospyros cordifolia Roxb & $V=0.024814-0.578532 \cdot D+6.11017 \cdot D^{2}$ & 0.760 \\
\hline 13 & Diospyros ebenum J.Koenig ex Retz. & $V=0.024814-0.578532 \cdot D+6.11017 \cdot D^{2}$ & * \\
\hline 14 & Diospyros ovalifolia Wight. & $V=(-0.184139+2.89723 \cdot D)^{2}$ & 0.760 \\
\hline 15 & Ehretia ovalifolia Wight. & $V=0.0790+0.4149 \cdot D^{2} H$ & 0.600 \\
\hline 16 & Euphorbia antiquorum $\mathrm{L}$ & $V=-0.0287+0.48016 \cdot D^{2} H$ & * \\
\hline 17 & Ficus microcarpa L.f. & $V=0.0153+0.3856 \cdot D^{2} H$ & 0.530 \\
\hline 18 & Ficus sp. & $V=0.0153+0.3856 \cdot D^{2} H$ & * \\
\hline 19 & Gmelina arborea Roxb. & $V=0.25058-3.55124 \cdot D+16.41720 \cdot D^{2}$ & 0.470 \\
\hline 20 & Grewia villosa Willd. & $V=0.015+0.281 \cdot D^{2} H$ & 0.651 \\
\hline 21 & Gyrocarpus americanus Jacq. & $G V=0.16948-1.85075 \cdot D+10.63682 \cdot D^{2}$ & 0.305 \\
\hline 22 & Hardwickia binata Roxb.(Endemic) & $V=-0.023583+0.279452 \cdot D^{2} H$ & 0.733 \\
\hline 23 & Ixora pavetta Andr. & $G V=0.16948-1.85075 \cdot D+10.63682 \cdot D^{2}$ & 0.860 \\
\hline 24 & Lepisanthes tetraphylla (Vahl) Radlk. & $G V=0.16948-1.85075 \cdot D+10.63682 \cdot D^{2}$ & * \\
\hline 25 & Mitrephora heyneana (Hook. f. \& Thomson) Thwaites & $G V=0.16948-1.85075 \cdot D+10.63682 \cdot D^{2}$ & 0.645 \\
\hline 26 & Pleiospermium alatum (Wight \& Arn.) Swingle & $G V=0.16948-1.85075 \cdot D+10.63682 \cdot D^{2}$ & 0.890 \\
\hline 27 & Sapindus emarginatus Vahl & $G V=0.16948-1.85075 \cdot D+10.63682 \cdot D^{2}$ & * \\
\hline 28 & Strychnos nux-vomica L. & $G V=0.16948-1.85075 \cdot D+10.63682 \cdot D^{2}$ & 0.750 \\
\hline 29 & Strychnos potatorum L.f. & $G V=0.16948-1.85075 \cdot D+10.63682 \cdot D^{2}$ & 0.840 \\
\hline 30 & Tamarindus indica $\mathrm{L}$. & $G V=0.16948-1.85075 \cdot D+10.63682 \cdot D^{2}$ & 0.960 \\
\hline 31 & Terminalia arjuna (Roxb. ex DC.) Wight \& Arn. & $V=-0.033-0.526 \cdot D+6.396 \cdot D^{2}$ & * \\
\hline 32 & Vitex leucoxylon L.f. & $V=0.066+0.287 \cdot D^{2} H$ & 0.771 \\
\hline
\end{tabular}

diameter at breast height $(\mathrm{DBH} \geq 3 \mathrm{~cm})$ and tree height were recorded with respect to species. All tree species were identified with the help of regional flora of Sasidharan (1999) and other standard floras. Tree height was measured with a Blume-Leiss hypsometer and the diameter was measured at breast height using a diameter tape. The study was carried out during 2011-2012.

\section{Aboveground stem biomass ( $A G B)$ of} trees with $\mathrm{DBH} \geq 10 \mathrm{~cm}$

For trees having $\mathrm{DBH} \geq 10 \mathrm{~cm}$, the aboveground phytomass (stem biomass) was calculated by multiplying the volume calculated for individual trees by wood specific gravity in the respective plot (Brown 1997, Ravindranath \& Ostwald 2008). Biomass was expressed as stem dry weight and measured in tonnes $(t)$. Tree volume was calculated using species-specific volume equations developed by Forest Survey of India (FSI 1996) - Tab. 1), using the diameter at breast height (DBH or D) and height (H) as inputs. Area-specific generalized volume equations developed by FSI were selected for those species for which equations were not available. Wood specific gravity data was obtained from Indian
Council of Forestry Research and Education (ICFRE 2002 - Tab. 1). For those tree species whose species-specific gravity was not available, an area-specific average gravity was calculated. The obtained stem biomass of each tree was then summed up within each plot to obtain the plot-level biomass (t $0.1 \mathrm{ha}^{-1}$ ).

\section{Basal area}

Basal area (BA) was calculated as the sum of cross-sectional area $\left(\mathrm{m}^{2}\right)$ measured at breast height $(1.3 \mathrm{~m})$ of all trees in each plot, according to Hedl et al. (2009).

\section{AGB of trees with $\mathrm{DBH}<10 \mathrm{~cm}$}

As trees belonging to small diameter classes (diameter $3-9 \mathrm{~cm}$ ) are generally ignored due to the lack of suitable equations, biomass estimation of trees with $<10$ $\mathrm{cm}$ DBH was assessed by developing suitable regression equation relating the basal area and stem biomass in the plots (Dadhwal et al. 2009). The detailed methodology is described below (see also Fig. 2).

Firstly, the basal area $\left(\mathrm{m}^{2} 0.1 \mathrm{ha}^{-1}\right)$ of trees with $\mathrm{DBH} \geq 10 \mathrm{~cm}$ and the basal area of all trees with $\mathrm{DBH} \geq 3 \mathrm{~cm}$ were calculated in each plot. Stem biomass of trees with $\mathrm{DBH}$ $\geq 10 \mathrm{~cm}$ was obtained by multiplying the volume by specific gravity and then correlated with the basal area of trees with $\mathrm{DBH}$ $\geq 10 \mathrm{~cm}$. A linear regression model was used as follows (eqn. 1):

$$
Y=m x+c
$$

where $Y$ is the biomass ( $0.1 \mathrm{ha}^{-1}$ ), $\mathrm{c}$ is the intercept, $m$ is the line slope, and $x$ is the basal area of trees $\left(\mathrm{m}^{2} 0.1 \mathrm{ha}^{-1}\right)$.

Linear regression coefficients $(m, c)$ obtained from the above model were applied on the basal area of trees with $\mathrm{DBH} \geq 10 \mathrm{~cm}$ and on the basal area of all trees $(\geq 3 \mathrm{~cm}$ diameter) in the plot to obtain the biomass of the respective components. Within each plot, the difference in biomass between trees with $\mathrm{DBH} \geq 3 \mathrm{~cm}$ and $\mathrm{DBH} \geq 10 \mathrm{~cm}$ within a plot was obtained as follows (eqn. 2):

$$
Y=\left(m x_{1}+c\right)-\left(m x_{2}+c\right)
$$

where $Y$ is the biomass of trees with $\mathrm{DBH}<$ $10 \mathrm{~cm}, \mathrm{~m}$ and $\mathrm{c}$ are constants, $X_{1}$ is the total basal area of all trees with $\mathrm{DBH}>3 \mathrm{~cm}$, and $x_{2}$ is the basal area of trees with $\mathrm{DBH} \geq 10$ $\mathrm{cm}$.

The difference (biomass of trees with $\mathrm{DBH}<10 \mathrm{~cm}$ ) was then added to the total 


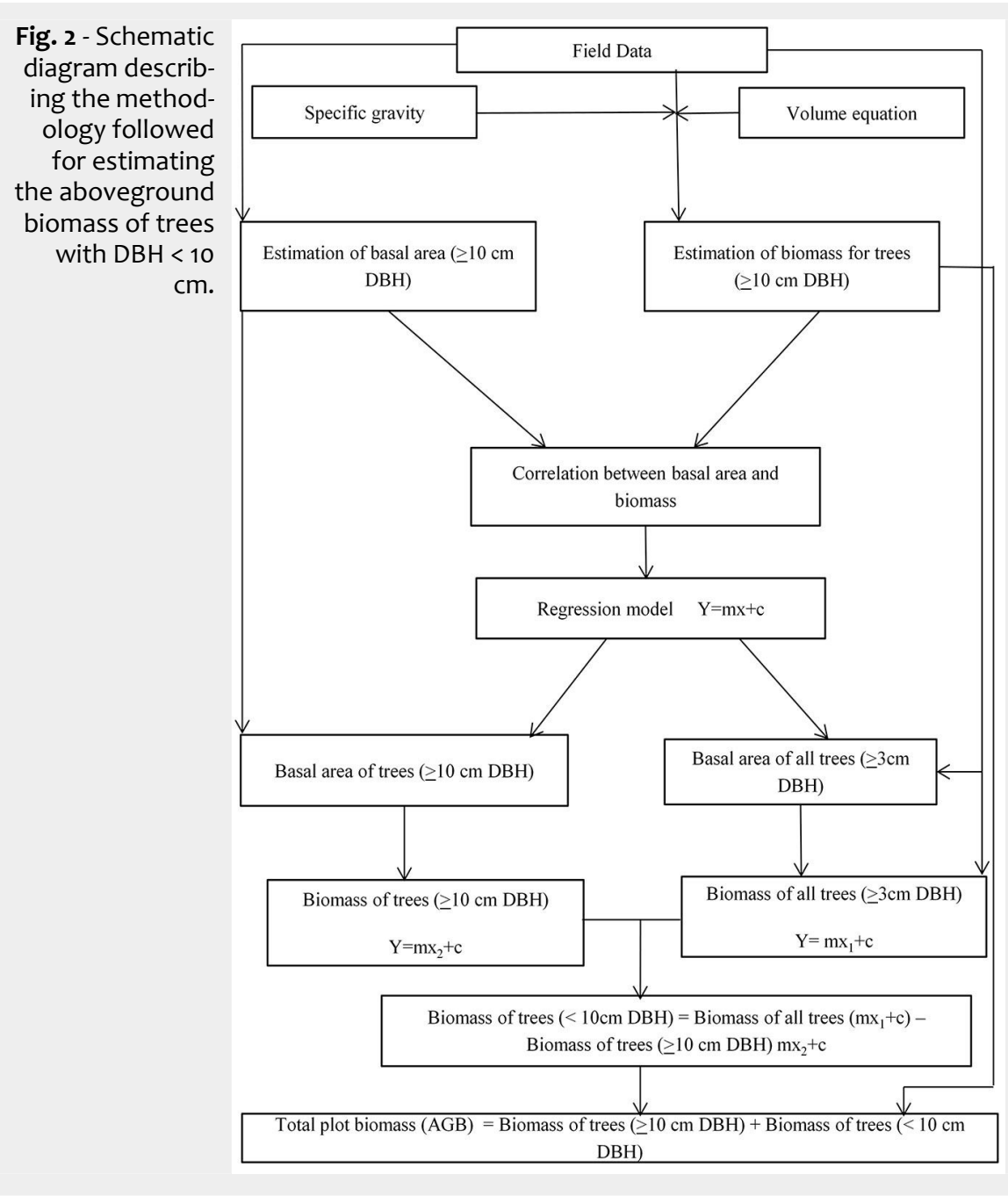

estimated biomass of trees with $\mathrm{DBH} \geq 10$ $\mathrm{cm}$ (volume $\times$ specific gravity) to obtain the total plot biomass (stem biomass) in $t 0.1$ ha ${ }^{-1}$, which was finally extrapolated into tonnes per hectare $\left(\mathrm{t} \mathrm{ha} \mathrm{a}^{-1}\right)$.

\section{Estimation of total biomass and carbon density of trees in the plot}

As canopy branches and leaves were not included in this study, the stem dry biomass was multiplied by a biomass expansion factor of 1.5 to obtain the total above ground biomass of each tree. The biomass expansion factor adopted in this study is species-based, according to the different density classes of Indian forest types previously reported (Kishwan et al. 2009). The below ground biomass (BGB) was calculated from the obtained aboveground biomass considering a shoot/root ratio of 0.26 (Cairns et al. 1997). This ratio is commonly used and did not differ much with respect to latitude, soil texture or tree type (Ravindranath \& Ostwald 2008). The total biomass within each plot was then obtained by summing $A G B$ and $B G B$. Since the carbon content varies from $45 \%$ to $50 \%$ of the total biomass in different ecosystems according to different studies, we cautiously considered the carbon content to be $47 \%$ of the dry woody biomass for regional- level carbon pool estimations (Raghubansi et al. 1990). Biomass values were then multiplied by a factor of 0.47 to obtain the amount of carbon existing in dry wood biomass. Biomass and carbon obtained from each subplot were summed to obtain the site standing biomass and carbon (expressed in tonnes dry weight). The average value of the standing biomass and carbon of the eight subplots was thus considered as the total biomass and carbon density of the forest ecosystem, expressed in $\mathrm{t} \mathrm{ha}^{-1}$.

\section{Relationship between carbon and other} dendrometric variables

Pearson's correlation analysis was carried out using the software SPSS ${ }^{\circledast}$ ver. 12.0 to test the relationship between carbon density and other dendrometric variables like tree density (in terms of number of trees), basal area and tree diversity (in terms of number of species). To this purpose, both species- and plot-wise correlation approaches were adopted. As for the former, all the species occurring in different subplots were taken together and the relationships among variables examined, whereas in the case of plot-wise correlation, the relationships among variables was examined across the 8 subplots, regardless of the species.

\section{Results and discussion}

\section{General characteristics of the forest}

A large heterogeneity of tree diameter and height was observed among the subplots, reflecting the growth differences among different tree species in each subplot (Tab. 2, Tab. 3). Indeed, tree growth is highly variable in the tropical forest (Feeley et al. 2007), thus a detailed appraisal of species composition, environmental and genetic factors, ecological history, management practices (especially in the context of climate change), is required in order to comprehend growth variations of tree species in the forest. Further, previous studies suggested that climate change can affect the distribution of tree species in the forest (Zhu et al. 2012) which in turn will change the regional patterns of forest biodiversity even at the plot level (Potter \& Woodall 2012).

\section{Estimation of biomass, carbon and} other dendrometric variables

Tree density (number of trees) ranged ranging from 35 to 112 trees for the 32 species recorded in this study. The average DBH of the subplots varied between 5.84 and $20.25 \mathrm{~cm}$. Tree height ranged between 2.81 and $5.94 \mathrm{~m}$, whereas the total basal area ranged between 0.27 and $3.4 \mathrm{~m}^{2}$ across subplots. The estimated $A G B$ varied between 1.22 and $15.98 \mathrm{t} 0.1 \mathrm{ha}^{-1}$ and BGB varied between 0.31 and 4.15 t $0.1 \mathrm{ha}^{-1}$. Combining $A G B$ and $B G B$ over all the plots and computing its weighted average, the total tree biomass (dry weight) of the site was found to be $64.13 \pm 23.65 \mathrm{t} \mathrm{ha}^{-1}$. Since the carbon constitutes generally half of the biomass weight (dry weight), in this study the carbon density of the tropical dry forest was estimated to be $30.46 \pm 11.23 \mathrm{t}-\mathrm{C}$ ha ${ }^{-1}$ (Tab. 2).

According to Murphy \& Lugo (1986), the aboveground carbon density in tropical dry forest varies between 14 and $123 \mathrm{t}-\mathrm{C} \mathrm{ha-1}$. Chaturvedi et al. (2011) reported a carbon density ranging from 15.6 to $151 \mathrm{t}-\mathrm{C} \mathrm{ha}^{-1}$ in tropical dry forests of India. Even though the above ground biomass carbon (AGBC) obtained in the present study is well within the limits of tropical dry forests, the results obtained are comparatively lower than the values reported in other tropical dry forest of India and elsewhere (Návar 2009). This might be due to a larger number of short structured trees or younger stands $(3-9 \mathrm{~cm}$ DBH, 10-69 DBH) compared to larger trees $(>70 \mathrm{DBH} \mathrm{cm})$ in the studied area. Moreover, the loss of water accumulated in the stem would result in a reductions in stem diameter of trees in the dry (deciduous) forest (Daubenmire 1972). Hence, the observed dendrobiometric variables (DBH, height, basal area and biomass) likely reflect the preponderance of short structured trees, mainly shaped by the climatic conditions of the area (Tab. 2).

The tropical dry forest is composed of a mosaic of different plant types showing 
Tab. 2 - Estimated values ( \pm standard error, SE) of biomass, carbon and other dendrometric variables in the 8 subplots analyzed. (n): Total number.

\begin{tabular}{|c|c|c|c|c|c|c|c|c|c|}
\hline \multirow{2}{*}{ Variable } & \multicolumn{8}{|c|}{ Subplot } & \multirow{2}{*}{ Average $\pm \mathrm{SE}$} \\
\hline & 1 & 2 & 3 & 4 & 5 & 6 & 7 & 8 & \\
\hline Tree density (stems $0.1 \mathrm{ha}^{-1}$ ) & 55 & 59 & 53 & 67 & 112 & 57 & 35 & 45 & $\begin{array}{c}60.37 \pm 8.11 \\
(n=483)\end{array}$ \\
\hline Tree density (stems ha-1) & 550 & 590 & 530 & 670 & 1120 & 570 & 350 & 450 & $\begin{array}{c}603.75 \pm 81.13 \\
(n=4830)\end{array}$ \\
\hline Average DBH (cm) & 14.69 & 8.67 & 10.39 & 8.85 & 5.84 & 20.25 & 8.55 & 7.38 & $10.57 \pm 4.69$ \\
\hline Average height (m) & 5.01 & 3.41 & 4.68 & 3.9 & 2.81 & 5.94 & 3.64 & 3.68 & $4.13 \pm 0.36$ \\
\hline Number of species (species $0.1 \mathrm{ha}^{-1}$ ) & 8 & 10 & 12 & 8 & 10 & 19 & 10 & 8 & $\begin{array}{c}10.625 \pm 1.29 \\
(n=32)\end{array}$ \\
\hline Total tree basal area $\left(\mathrm{m}^{2} 0.1 \mathrm{ha}^{-1}\right)$ & 1.4 & 0.79 & 0.79 & 0.49 & 0.34 & 3.4 & 0.33 & 0.27 & $0.98 \pm 0.38$ \\
\hline Total tree basal area $\left(\mathrm{m}^{2} \mathrm{ha}^{-1}\right)$ & 14.05 & 7.88 & 7.88 & 4.93 & 3.43 & 34.96 & 3.27 & 2.73 & $9.89 \pm 3.82$ \\
\hline Total AGB (t $\left.0.1 \mathrm{ha}^{-1}\right)$ & 10.53 & 3.32 & 3.30 & 2.90 & 1.22 & 15.98 & 1.39 & 2.05 & $5.08 \pm 1.88$ \\
\hline Total AGB (t ha-1) & 105.3 & 33.2 & 33 & 29 & 12.2 & 159.8 & 13.9 & 20.5 & $50.86 \pm 18.8$ \\
\hline Total AGBC (t-C ha $\left.{ }^{-1}\right)$ & 50.02 & 15.77 & 15.68 & 13.78 & 5.80 & 75.91 & 6.60 & 9.74 & $24.15 \pm 8.91$ \\
\hline Total BGB (t $\left.0.1 \mathrm{ha}^{-1}\right)$ & 2.74 & 0.86 & 0.85 & 0.75 & 0.31 & 4.155 & 0.36 & 0.53 & $1.31 \pm 0.48$ \\
\hline Total tree biomass $-\mathrm{AGB}+\mathrm{BGB}\left(\mathrm{t} 0.1 \mathrm{ha}^{-1}\right)$ & 13.27 & 4.19 & 4.16 & 3.66 & 1.54 & 20.13 & 1.75 & 2.58 & $6.41 \pm 2.3$ \\
\hline Total tree carbon (t-C $\left.0.1 \mathrm{ha}^{-1}\right)$ & 6.30 & 1.99 & 1.97 & 1.73 & 0.73 & 9.56 & 0.83 & 1.22 & $3.04 \pm 1.12$ \\
\hline Total tree biomass $-\mathrm{AGB}+\mathrm{BGB}\left(\mathrm{t} \mathrm{ha}{ }^{-1}\right)$ & 132.78 & 41.9 & 41.63 & 36.62 & 15.4 & 201.38 & 17.52 & 25.83 & $64.13 \pm 23.65$ \\
\hline Total tree carbon $\left(\mathrm{t}-\mathrm{C} \mathrm{ha}^{-1}\right)$ & 63.07 & 19.9 & 19.77 & 17.39 & 7.32 & 95.66 & 8.32 & 12.27 & $30.46 \pm 11.23$ \\
\hline
\end{tabular}

varying adaptations to seasonal drought (Borchert 2000). Local differences in the extent and intensity of seasonal drought might have caused (to some extent) the observed spatial variation in the carbon content between plots. Moreover, the presence of a stream running near some of the study subplots could have locally reduced the water stress by keeping the soil moister and supplied trees with more nutrients, thus favoring tree growth as compared with the dry conditions occurring across the region. The occurrences in the examined plots of large species such as Terminalia arjuna (Roxb. ex DC.) Wight \& Arn. and Vitex leucoxylon L.f which are generally found along stream banks, can support the above considerations. Furthermore, the intensity of human disturbance across the forest could be highly heterogeneous. Hence, the spatial heterogeneity of carbon density among the studied plots can be attributed to various biotic, abiotic and anthropogenic factors. Nonetheless, the carbon density values observed in this study are comparatively lower than those reported for other forest types in India
Tab. 3 - Species-wise (top 5 species with $\mathrm{DBH}>10 \mathrm{~cm}$ ) contribution to carbon storage recorded in the eight subplots, covering an overall area of 0.8 ha.

\begin{tabular}{llcccc}
\hline No. & Species & $\begin{array}{c}\text { Tree density } \\
\text { (no. trees) }\end{array}$ & $\begin{array}{c}\text { Total tree } \\
\text { basal area } \\
\left(\mathbf{m}^{2}\right)\end{array}$ & $\begin{array}{c}\text { Total tree } \\
\text { carbon (t) }\end{array}$ & $\begin{array}{c}\text { Average tree } \\
\text { carbon (t) }\end{array}$ \\
\hline 1 & Tamarindus indica L. & 8 & 1.36 & $3.76(17 \%)$ & 0.47 \\
\hline 2 & Hardwickia binata Roxb. & 2 & 0.67 & $3.10(14 \%)$ & 1.55 \\
\hline 3 & $\begin{array}{l}\text { Terminalia arjuna (Roxb. } \\
\text { ex DC.) Wight \& Arn. }\end{array}$ & 1 & 0.97 & $2.35(10 \%)$ & 2.35 \\
\hline 4 & $\begin{array}{l}\text { Pleiospermium alatum } \\
\text { (Wight \& Arn.) Swingle }\end{array}$ & 31 & 0.41 & $2.27(10 \%)$ & 0.07 \\
\hline 5 & Atalantia monophylla DC. & 23 & 0.29 & $1.44(6 \%)$ & 0.06 \\
\hline
\end{tabular}

(tropical moist deciduous forests, tropical in the forest system was contributed by disemi-evergreen forests, tropical evergreen ameter class $\geq 10 \mathrm{~cm}$, with a tree density forests and tropical rainforests - Baishya et share of 33\% when compared to the other al. 2009, Saatchi et al. 2011).

Species-wise contribution to carbon storage and its relationship with other dendrometric variables

In this work, we aimed to identify the leading carbon storing species in the area by considering trees with $\mathrm{DBH}>10 \mathrm{~cm}$. A substantial portion of carbon density ( $92 \%)$ class (DBH $<10 \mathrm{~cm}$ ) of trees (see below). Among the 32 species recorded in the selected area, Tamarindus indica L. showed the maximum carbon storage capacity (17\%) followed by Hardwickia binata Roxb. (14\%), Terminalia arjuna (Roxb. ex DC.) Wight \& Arn. (10\%) and Pleiospermium alatum (Wight \& Arn.) Swingle (10\% - Tab. 3). These top four species stored almost half
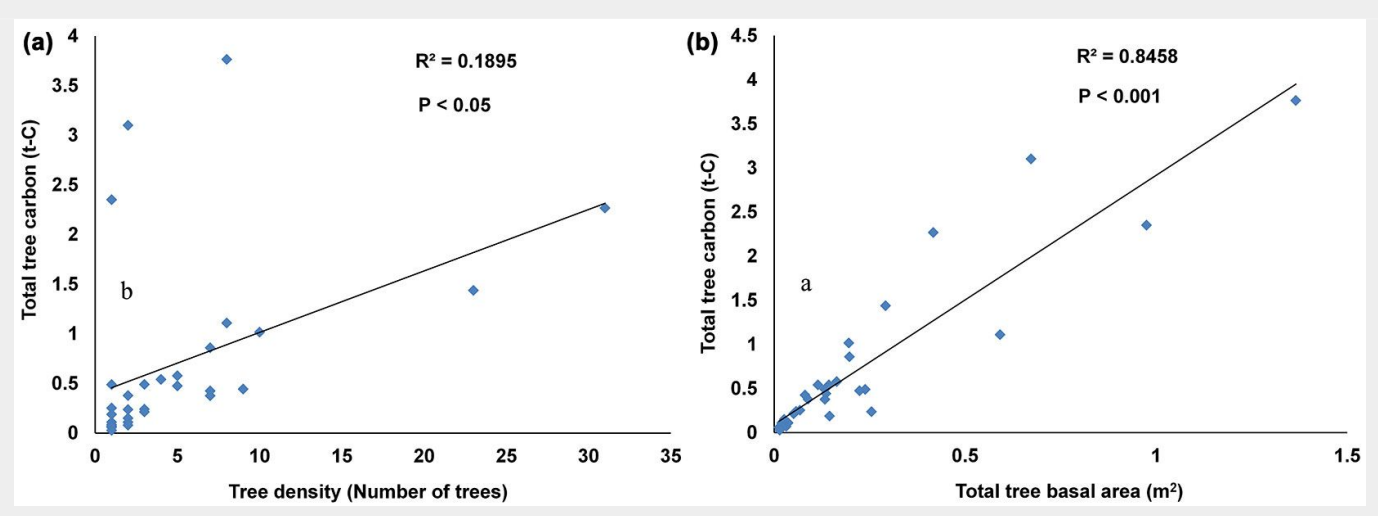

Fig. 3 - Species-wise $(32$ species with $\geq 10 \mathrm{~cm} \mathrm{DBH}$ ) relationship between carbon and other dendrometric variables recorded from the eight subplots ( $0.8 \mathrm{ha}$ ). (a) Tree carbon and tree density; (b) tree carbon and basal area. 

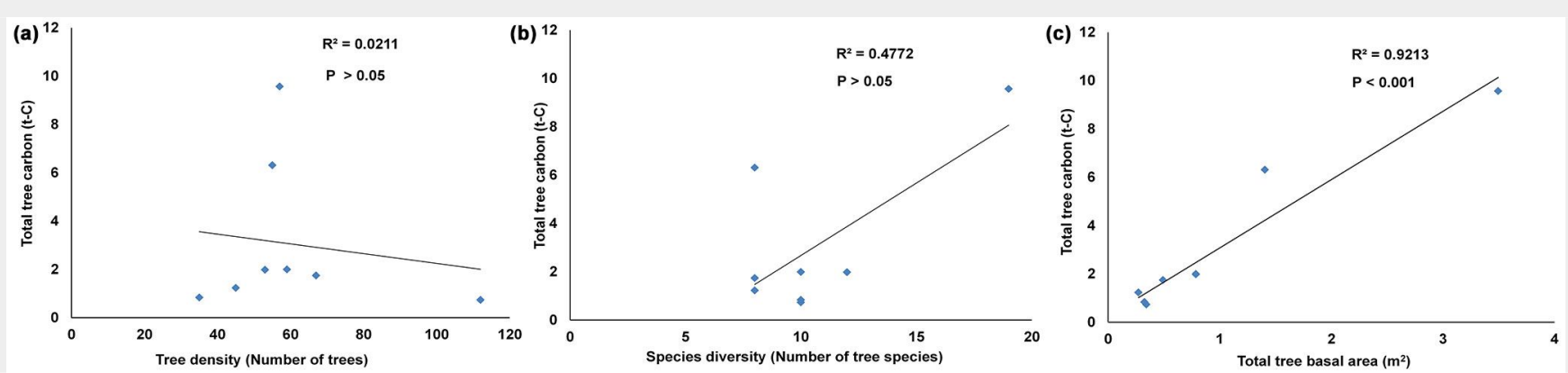

Fig. 4 - Plot-wise (0.1 ha area) relationship between carbon and other dendrometric variables. (a) Tree carbon and tree density; (b) tree carbon and tree diversity (number of tree species); (c) tree carbon and basal area.

the carbon (50.90\%) that is stored by all the dominant species identified in the area. It is worth noting that Tamarindus indica is not native to this region and commonly confined to areas adjacent to human settlements, though its wide use as for food and medicines could have contributed to its spread in the studied area. In addition, the favorable conditions provided by the stream might also have influenced its luxuriant growth. However, in the context of conservation, the relative significance of native and non-native species are to be studied with respect to their ecosystem functions.

Tree size coupled with tree density provides an indication of the aboveground carbon storage, which is an important parameter of forest structure (Nagendra 2012). The result indicated that species-wise tree carbon $(\mathrm{DBH} \geq 10 \mathrm{~cm})$ had a strong positive correlation with basal area $\left(R^{2}=0.84, p<\right.$ 0.001). Such parameter may be conveniently used as an indicator for biomass and carbon, since it integrates the effect of both the number and size of trees (Burrows et al. 2000). On the other hand, tree carbon showed a weak (though significant) positive relationship with tree density $\left(R^{2}=\right.$
$0.18, p<0.05-$ Fig. 3a, Fig. 3b). All the above findings could help selecting the most suitable species and species combinations for enhancing carbon sequestration in the studied area.

\section{Plot-wise relationship between carbon} and other dendrometric variables

In this study, we examined the relationship between carbon and other tree variables of the different studied plots using all the trees, regardless of their diameter (DBH $<10 \mathrm{~cm}$ and $\mathrm{DBH} \geq 10 \mathrm{~cm}-$ Fig. $4 \mathrm{a}$, Fig. 4b, Fig. 4c). In this case, tree density showed a non-significant negative relationship with carbon $\left(R^{2}=0.02, p=0.731\right)$. This might be due to the occurrence of a large number of small trees (DBH 3-9 cm) in different plots, which altogether constitute $67 \%$ of trees and represent a negligible ( $8 \%$ ) carbon share in the area (Fig. 5). Thus, the plot-wise correlation analysis revealed that forest plots with higher tree density are not rich in carbon. This finding is in agreement with the evidence that carbon in tree biomass increases with $\mathrm{DBH}$, basal area and height, but not with tree density (Hui et al. 2012). Pragasan (2014) observed a positive relationship between tree density

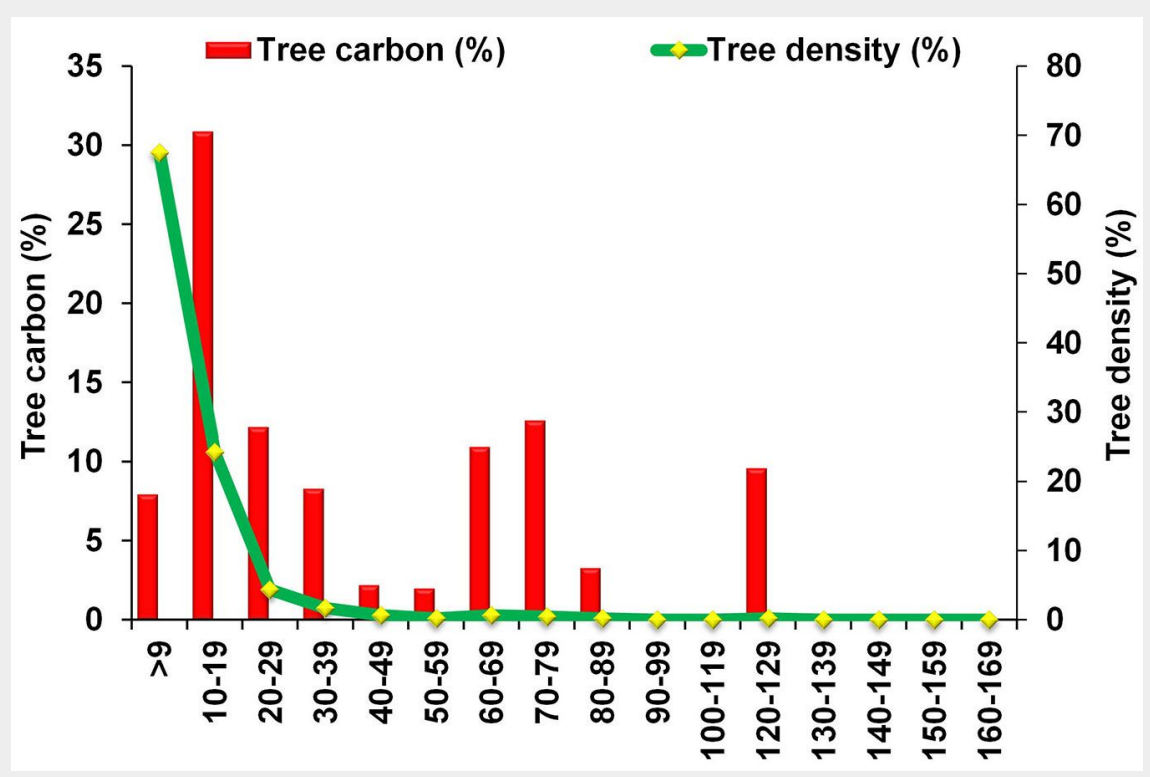

Fig. 5 - Distribution of tree density (\%) and tree carbon (\%) across different diametric classes. and carbon in the case of plot-wise correlation, when trees with $\mathrm{DBH}>10 \mathrm{~cm}$ were considered.

Tree diversity (in terms of number of species) also showed a moderate positive relationship with carbon density, though not significant $\left(R^{2}=0.47, p=0.058\right)$. These results are in agreement with the available literature (Borah et al. 2013). It may be inferred that promoting tree diversity may accelerate $\mathrm{CO}_{2}$ sequestration from the atmosphere to a certain extent and thus be relevant in a climate-change context. Although some experimental works carried out in different ecosystems showed that plant diversity often promotes stability and primary productivity and consequently carbon accumulation (Miles et al. 2010), the relationship between plant diversity and carbon density in tropical forests still remains unclear.

In this study, the strong positive relationship observed between carbon density and basal area $\left(R^{2}=0.92, p<0.001\right)$ is in accordance with numerous previous studies in India (Mani \& Parthasarathy 2007, Chaturvedi et al. 2011). Moreover, the kind of association established between carbon and basal area could also be used in predicting forest carbon in the region.

Overall, the results of the correlation analysis (both species- and plot-wise) indicate that basal area has a strong relationship with carbon storage, while contrasting results have been obtained with tree density and tree diversity. This is contrary to our first hypothesis that all the three variables could be considered as good indicators of biomass and carbon storage in the forest.

Resolving the relationship of dendrometric variables with carbon stock is central to predict their possible contribution to climate change mitigation. Without understanding the interactions between these factors, it is difficult to predict the effects of future change on carbon cycling or translate results between sites with different characteristics.

\section{Diametric class distribution of tree density and carbon}

The diameter distribution of trees can be used as an indicator of changes in population structure and species composition 
(Newbery \& Gartlan 1996). Regarding the tree density, it has been reported that distribution curves that drop exponentially with increasing DBH (reverse J-shaped) are characteristic of species with continuous and sustainable regeneration (Khamyong et al. 2004). Such a trend has also been detected in forests of Great Andaman groups (Padalia et al. 2004), Saddle peak of North Andaman Islands (Tripathi et al. 2004) and Thailand (Khamyong et al. 2004). Moreover, diameter distribution across diametric classes can provide relevant information on how well site resources are exploited by the growing forest. Such a distribution is ecologically more informative when accompanied with data on the spatial distribution of individuals (Krebs 1989). Despite the extreme climatic conditions occurring in the area and the above-mentioned threats, our findings suggest that the studied forest has a good regeneration, as revealed by the higher density of small diametric classes (DBH 3-9 cm) compared to large diametric classes $(\mathrm{DBH} \geq 70 \mathrm{~cm}-$ Fig. 5).

The distribution of carbon contents across different diametric classes is considered the most important aspect when examining vegetation carbon storage of an area (Baishya et al. 2009). We observed a positively skewed distribution of carbon in the dry forest, with small- (DBH 3-9 cm) and medium-sized trees (10-69 cm DBH) contributing by more than $50 \%$ to total biomass and carbon (Fig. 5). This highlights the role of young stands (small to medium sized trees) in the carbon accumulation of tropical dry forest of Chinnar, and substantiates our second hypothesis that younger trees deeply affect carbon storage in tropical dry forest ecosystems. Previous studies showed that large trees $(\mathrm{DBH}>70 \mathrm{~cm}) \mathrm{can}$ play a vital role in carbon storage in forest ecosystem (Baishya et al. 2009), though small to medium trees have a prominent role in carbon storage of tropical dry forests (Brown et al. 1997, Borah et al. 2013).

Climatic variables such as temperature and rainfall had a major role in shaping the structural characteristics and species composition of the studied forest, thereby promoting scrubby (thorny) and deciduous vegetation characterized by trees of stunted growth and low diametric class (Singh \& Singh 1992). Other factors like relative humidity, soil fertility and moisture, elevation, topography, and disturbance may also affect the growth and development of tree species in the tropical dry forest of Chinnar, as previously reported for other parts of the Western Ghats (Joseph et al. 2012, Ramesh et al. 2010).

\section{Conclusions}

The biomass and carbon density of trees in the tropical dry forest of Kerala in Southern Western Ghats was estimated to be $64.13 \pm 23.65 \mathrm{t} \mathrm{ha}^{-1}$ and $30.46 \pm 11.23 \mathrm{t}-\mathrm{C} \mathrm{ha}^{-1}$, respectively, which are consistent with earlier studies. Based on our results, several species showing larger size with high carbon storage can be considered for afforestation/reforestation purposes to enrich the forest carbon density of the area.

Regarding our first hypothesis, we confirmed that basal area could be a useful proxy for biomass and carbon, while tree density and tree diversity gave inconclusive results. With respect to the second hypothesis, we found that smaller or moderate trees have greater carbon storage as compared to larger trees in the tropical dry forest.

Since our present findings are based on a limited field study dataset, further studies on shrubs, herbs, litter, deadwood, soil organic carbon and other biotic and abiotic factors are needed to substantiate the total carbon budget of the area. Further, replacing the general volume equations used in this study with more species-specific volume equations and the corresponding specific gravity for a vast majority of tree species in the dry forest, is required to improve the precision of estimates. Despite the above-mentioned limitations, considering the increasing importance of forest carbon sequestration and climate change mitigation, our findings and could help defining strategies for sustainable management and conservation of tropical dry forests, and also contributes to the national carbon inventory program of India.

\section{Acknowledgements}

We gratefully acknowledge the funding from the Indian Institute of Remote Sensing (IIRS), Dehradun, Indian Space Research Organisation (ISRO), Department of Space, Government of India. The authors acknowledge Directorate of Environment and Climate Change, Government of Kerala for the support extended for this work. We are grateful to members of School of Environmental Sciences for their assistance during data collection. The authors thank the Forest Department, Government of Kerala for the permission and assistance in data collection. We are indebted to Dr. Sarnam Singh for his invaluable contributions to the work. We express our gratitude to Dr. Susan Varghese, Prof. Jacob Eapen Kunnath, Dr. Appu Jacob John, and Prof. Vijo Thomas Kurian for proofreading and editing the manuscript. Finally, thanks to the anonymous reviewers for their criticism and their constructive comments that improved the quality of this manuscript.

\section{References}

Baishya R, Barik SK, Upadhaya K (2009). Distribution pattern of aboveground biomass in natural and plantation forests of humid tropics in northeast India. Tropical Ecology 50: 295-304. [online] URL: http://tropecol.com/pdf/open/PD F_50_2/J-10.pdf

Borah N, Nath AJ, Das KA (2013). Aboveground biomass and carbon stocks of tree species in tropical forests of Cachar District, Assam, Northeast India. International Journal of Ecology and Environmental Sciences 39 (2): 97-106.
Borchert R (2000). Organismic and environmental controls of bud growth in tropical trees. In: "Dormancy in Plants: from Whole Plant Behavior to Cellular Control" (Viemont CD, Crabb J eds). $C A B$ International, Wallingford, UK, 87107. [online] URL: http://books.google.com/boo ks?id=iYUmyC 9 DEgMC

Brown S, Schroeder P, Birdsey R (1997). Aboveground biomass distribution of US eastern hardwood forests and the use of large trees as an indicator of forest development. Forest Ecology and Management 96 (1-2): 37-47. - doi: 10.1016/S0378-1127(97)00044-3

Brown S (1997). Estimating biomass and biomass change of tropical forests: a primer. FAO Forestry Paper no. 134, Food and Agriculture Organization of the United Nations (FAO), Rome, Italy, pp. 55. [online] URL: http://books. google.com/books?id=uv-ISezvitwC

Burrows WH, Hoffmann MB, Compton JF, Back PV, Tait $L$ (2000). Allometric relationships and community biomass estimates for some dominant Eucalypts in central Queensland woodlands. Australian Journal of Botany 48: 707-714. - doi: 10.1071/BT99066

Cairns MA, Brown S, Helmer EH, Baumgardner GA (1997). Root biomass allocation in the world's upland forests. Oecologia 111: 1-11. - doi: 10.1007/s004420050201

Canadell JG, Raupach MR (2008). Managing forests for climate change mitigation. Science 320 (5882): 1456-1457. - doi: 10.1126/science.115 5458

Chandrashekara UM, Menon ARR, Nair KKN, Sasidharan N, Swarupanandan K (1998). Evaluating plant diversity in different forest types of Kerala by laying out permanent sample plots. KFRI Research Report no. 156, Peechi, India, pp. 86.

Chaturvedi RK, Raghubanshi AS, Singh JS (2011). Leaf attributes and tree growth in a tropical dry forest. Journal of Vegetation Science 22 (5): 917-931. - doi: 10.1111/j.1654-1103.2011.01299.x

Dadhwal VK, Singh S, Patil P (2009). Assessment of phytomass carbon pools in forest ecosystems in India. NNRMS Bulletin, Indian Institute of Remote Sensing, Dehradun, India, pp. 41-47. Daubenmire R (1972). Phenology and other characteristics of tropical semi-deciduous forest in northwestern Costa Rica. Journal of Ecology 60: 147. - doi: 10.2307/2258048

Dirzo R, Young HS, Mooney HA, Ceballos G (2011). Seasonally dry tropical forests, ecology and conservation. Island Press, Washington, DC, USA, vol. XIV, pp. 394. [online] URL: http:// books.google.com/books?id=TRo4kGgSCKEC

Feeley KJ, Joseph Wright S, Nur Supardi MN, Kassim AR, Davies SJ (2007). Decelerating growth in tropical forest trees. Ecology Letters 10 (6): 461-469. - doi: 10.1111/j.1461-0248.2007.01 033.x

Foley JA (1995). An equilibrium model of the terrestrial carbon budget. Tellus 47B: 310-319. doi: 10.3402/tellusb.v47i3.16050

FSI (1996). Volume equations for forests of India, Nepal and Bhutan. Forest Survey of India, Ministry of Environment and Forests. Govt. Of India, Dehradun, India, pp. 249.

Gibbs HK, Brown S, Niles JO, Foley JA (2007). Monitoring and estimating tropical forest carbon stocks: making REDD a reality. Environ- 
mental Research Letters 2 (4): 045023. - doi: 10.1088/1748-9326/2/4/045023

Hedl R, Svatek M, Dancak M, Rodzay AW, Salleh $A B$, Kamariah AS (2009). A new technique for inventory of permanent plots in tropical forests: a case study from lowland dipterocarp forest in Kuala Belalong, Brunei Darussalam. Blumea 54: 124-130. - doi: 10.3767/000651909X4 75482

Hui D, Wang J, Le X, Shen W, Ren H (2012). Influences of biotic and abiotic factors on the relationship between tree productivity and biomass in China. Forest Ecology and Management 264: 72-80. - doi: 10.1016/j.foreco.2011.10. 012

ICFRE (2002). Indian woods: their identification, properties and uses. Indian Council of Forestry Research and Education (ICFRE), Dehradun, India, vol. I-VI, pp. 1431.

IPCC (2006). Guidelines for national greenhouse gas inventories. Vol. 4: Agriculture, forestry and other land use (AFLOLU). Intergovernmental Panel on Climate Change (IPCC), Institute for Global Environmental Strategies, Hayama, Japan, pp. 1-83.

Joseph S, Anitha K, Srivastava VK, Reddy CS, Thomas AP, Murthy MSR (2012). Rainfall and elevation influence the local-scale distribution of tree community in the southern region of Western Ghats biodiversity hotspot (India). International Journal of Forestry Research 2012 (4387): 1-10. - doi: 10.1155/2012/576502

Kallarackal J, Somen CK (1999). Weather data acquisition from selected Wildlife Sanctuaries in Kerala. KFRI Research Report no. 176, Peechi, India, pp. 200.

KFD (2012). Management plan for Chinnar Wildlife Sanctuary 2012-2013 to 2021-2022. Kerala Forest Department (KFD), Department of Forest and Wildlife, Government of Kerala, India, pp. 202.

Khamyong S, Lykke AM, Seramethakun D, Barfod AS (2004). Species composition and vegetation structure of an upper montane forest at summit of Mt. Doi Inthanon, Thailand. Nordic Journal of Botany 23: 83-97. - doi: 10.1111/j.17561051.2003.tbo0371.x

Kishwan J, Pandey R, Dadhwal VK (2009). India's forest and tree cover: contribution as a carbon sink. Technical Paper no. 130 ICFRE BL-23, Indian Council of Forestry Research and Education, Dehradun, India, pp. 12.

Korner C, Asshoff R, Bignucolo O, Hättenschwiler S, Keel SG, Perláez-Riedl S, Pepin S, Siegwolf RTW, Zotz G (2005). Carbon flux and growth in mature deciduous forest trees exposed to elevated $\mathrm{CO}_{2}$. Science 309: 1360-1362. - doi: 10.1126/science.1113977

Krebs CJ (1989). Ecological methodology. Harper and Row, New York, USA, pp. 654.

Mani S, Parthasarathy N (2007). Above-ground biomass estimation in ten tropical dry ever- green forest sites of peninsular India. Biomass and Bioenergy 31 (5): 284-290. - doi: 10.1016/j. biombioe.2006.08.006

Miles L, Dunning E, Doswald N, Osti M (2010). A safer bet for REDD+: review of the evidence on the relationship between biodiversity and the resilience of forest carbon stocks. Working $\mathrm{Pa}$ per v2, Multiple Benefits Series 10, UN-REDD Programme, UNEP World Conservation Monitoring Centre, Cambridge, UK, pp. 35.

Miles L, Newton AC, DeFries RS, Ravilious C, May I, Blyth S, Kapos V, Gordon JE (2006). A global overview of the conservation status of tropical dry forests. Journal of Biogeography 33: 491505. - doi: 10.1111/j.1365-2699.2005.01424.x

Molur S, Smith KG, Daniel BA, Darwall WRT (2011). The status and distribution of freshwater biodiversity in the Western Ghats, India. IUCN and Zoo Outreach Organisation, Cambridge, UK and Gland, Switzerland, pp. 1-116.

Mooney HA, Bullock SH, Medina E (1995). Introduction. In: "Dry Tropical Forests" (Mooney HA, Bullock SH, Medina E eds). Cambridge University Press, Cambridge, UK, pp. 1-8.

Murphy PG, Lugo AE (1986). Ecology of tropical dry forest. Annual Review of Ecology and Systematics 17: 67-88. - doi: 10.1146/annurev.es.17. 110186.000435

Nagendra H (2012). Assessing relatedness and redundancy of forest monitoring and change indicators. Journal of Environmental Management 95: 108-113. - doi: 10.1016/j.jenvman.2011. 10.002

Návar J (2009). Allometric equations for tree species and carbon stocks for forests of northwestern Mexico. Forest Ecology and Management 257: 427-434. - doi: 10.1016/j.foreco.2008. 09.028

Newbery Mc DC, Gartlan JS (1996). A structural analysis of rain forest at Korup and DoualaEdea Cameroon. Proceedings of the Royal Society of Edinburgh B - Biological Sciences 104: 177-224. [online] URL: http://www.cambridge. org/core/journals/8704E7C36B934967BADD6D 736033 EFEB

Padalia H, Chauhan N, Porwal MC, Roy PS (2004). Phytosociological observations on tree species diversity of Andaman Islands, India. Current Science 87: 799-806. [online] URL: http://www.jstor.org/stable/24109360

Potter KM, Woodall CW (2012). Trends over time in tree and seedling phylogenetic diversity indicate regional differences in forest biodiversity change. Ecological Applications 22: 517-531. doi: 10.1890/10-2137.1

Pragasan LA (2014). Carbon stock assessment in the vegetation of the Chitteri Reserve Forest of the Eastern Ghats in India based on non-destructive method using tree inventory data. Journal of Earth Science and Climatic Change S11- 001: 1-9.

Raghubansi AS, Jha CS, Pandey CB, Singh L,
Singh JS (1990). Effects of forest conversion on vegetation and soil carbon and functional trait of resulting vegetation. In: "Impact of Global Climate Changes on Photosynthesis and Plant Productivity" (Abrol YP, Wattal PN, Gnanum A, Govindji Ort DR, Teramura AH eds). Oxford and IBH Publishing Company, New Delhi, India, pp. 723-749.

Ramesh BR, Venugopal PD, Pelissier R, Patil SV, Swaminath $\mathrm{MH}$, Couteron P (2010). Mesoscale patterns in the floristic composition of forests in the central Western Ghats of Karnataka, India. Biotropica 42 (4): 435-443. - doi: 10.1111/j.17 44-7429.2009.00621.x

Ravindranath NH, Ostwald M (2008). Carbon inventory methods handbook for greenhouse gas inventory, carbon mitigation and round wood production projects. Springer, Netherlands, vol. 29, pp. 306.

Reddy CS, Jha CS, Diwakar PG, Dadhwal VK (2015). Nationwide classification of forest types of India using remote sensing and GIS. Environmental Monitoring and Assessment 187 (12): 1959. - doi: 10.1007/s10661-015-4990-8

Saatchi SS, Harris NL, Brown S, Lefsky $M$, Mitchard ETA, Salas W, Zutta BR, Buermann W, Lewis SL, Hagen S, Petrova S, White L, Silman M, Morel A (2011). Benchmark map of forest carbon stocks in tropical regions across three continents. Proceedings of the National Academy of Sciences USA 108 (24): 9899-9904. - doi: 10.1073/pnas.1019576108

Sasidharan N (1999). Studies on the flora of Chinnar Wildlife Sanctuary. Research report no. 167, Kerala Forest Research Institute, Peechi, India, pp. 365.

Singh S, Dadhwal VK (2009). Manual on spatial assessment of vegetation carbon pool of India. Indian Institute of Remote Sensing, ISRO, Department of Space, Govt. of India, Dehradun, India, pp. 32.

Singh JS, Singh VK (1992). Phenology of seasonally dry tropical forest. Current Science 63: 684689. [online] URL: http://www.jstor.org/stable/ 24094777

Tripathi KP, Tripathi S, Selvan T, Kumar K, Singh KK, Mehrotra S, Pushpangadan P (2004). Community structure and species diversity of Saddle Peak forest in Andaman Island. Tropical Ecology 45: 241-250. [online] URL: http://www. researchgate.net/publication/315653474

Zhu K, Woodall CW, Clark JS (2012). Failure to migrate: lack of tree range expansion in response to climate change. Global Change Biology 18: 1042-1052. - doi: 10.1111/j.1365-2486.2011.02571.x

\section{Supplementary Material}

Tab. S1 - Observations from the forest ecosystems.

Link: Padmakumar_2190@supploo1.pdf 